gases. Experience has proved the powder method to be of more general application, and its use, in conjunction with Schlieren photography for locating flame boundaries, shows that the amount of air entrained by the above type of flame is approximately three times that required for complete combustion. About half the air required for complete combustion flows directly into the reaction zone, the remainder entering that zone by diffusion.

The satisfactory disposal of liquor effluents is a problem which has confronted the gas industry for some time, and one which has assumed greater importance recently as a result of increased gas prcduction, greater sewage flow generally, and new legislation governing the prevention of river pollution. The urgency of the problem was emphasized in two papers dealing with the treatment of gas-works liquor.

C. Cooper and W. E. Bouch outlined a new method of effluent liquor purification in which the residual toxic matter in ammonia stills and other gas-works effluents is destroyed by nitric acid and nitrous acid. Inorganic salts such as ammonium thiosulphate and thiocyanate are converted into comparatively harmless substances, while the decomposition products of the acid are recovered for further use by simple oxidation with air. On the other hand, some nitric acid is lost as a result of its combination with any phenolic bodies present in the effluent.

The second paper, by W. H. Blackburn, T. G. Tomlinson and T. H. Summers, discussed the treatment of gas-works liquor in admixture with sewage in percolating filters. As part of a long-term investigation into the identification and estimation of the constituents of gas liquor, a typical liquor has been divided into a number of fractions and the effect of each fraction on sewage purification determined separately. A new method for the fractionation of the liquor, using methyl isobutyl ketone as solvent, was devised and four main fractions obtained, that containing phenols being further sub-divided by distillation. The greatest deterioration in the quality of a domestic sewage effluent was afterwards shown to be caused by the addition of two fractions, one containing thiocyanate, ammonia and organic sub. stances not extracted from the liquor by the solvent, and the other containing carboxylic acids and 'humic acids'. Further, polyhydric phenols were shown to produce a greater deterioration in effluent quality than monohydric phenols.

Some aspects of the mechanism of the gasification of carbon by carbon dioxide and steam were discussed by J. D. F. Marsh. Laboratory experiments have shown that, when a sample of high-temperature coke is reduced by hydrogen and then treated with carbon dioxide at a temperature below that necessary for gasification, a reaction occurs producing carbon monoxide and a surface layer of adsorbed oxygen which can be removed as water vapour by subsequent treatment with hydrogen. If treated with carbon monoxide instead of hydrogen, most of the oxygen is removed as carbon dioxide; but on the reduced surface, carbon monoxide is then converted to carbon dioxide and carbon. These and other results are then used to elucidate the mechanisms for the reactions between carbon and carbon dioxide or steam.

Finally, the possibilities of recovering pure sulphur from gas-works spent oxide by extraction with toluene were discussed by F. A. Burden and W. B. S. Newling, while R. F. Hayman considered the application of flow visualization techniques to the design of small high-temperature, gas-fired furnaces.

\section{THE MICROSCOPE IN INDUSTRY}

TN Beck's microscope catalogue for 1865 there are engravings of what one supposes to have been typical subjects for the microscopist of that day. One of them is a beautifully drawn but revolting picture of a parasite "to be found in the follicles of the human skin, particularly about the nose. They are easily obtained by ...." Nowadays the microscope serves a more utilitarian purpose, and we may enjoy instead a picture of a speck of oil being coaxed from a soiled textile fibre by a gentle detergent. This particular study was one of many demonstrations set out at a recent exhibition in London to show "How Industry is Using the Microscope". The exhibition, organized by the Royal Microscopical Society, was held at British Medical Association House on November 21 and was opened by the director of the British Scientific Instrument Research Association, Mr. A. J. Philpot.

The microscope, unlike other industrial instruments, was not conceived for industry, and its value there has only in the past few decades been widely recognized. The present extent of its application to industrial problems is shown by the fact that the forty-two contributors to this exhibition came from a wide range of industries : mining and power, agriculture and food, metallurgy, ceramics and glass, paper, rubber, fabrics and leather, paint, pharmacy, photography and industrial biology. Several branches of these industries were appropriately represented by their research associations. If the subjects of the display must be classified, it is safe to say that more than half the exhibits were of applications of the microscope to process control and to the investigation of well-established manufacturing processes. Textiles, leather and cosmetics have been made since the distant time when the advantages of being well clothed, well shod and beautiful were first realized; for the greater part of this time 'process control' has meant no more than feeling, smelling and looking at the fabric or the ointment. Now the man in charge is being offered the support of scientific instruments : the microscope is used to follow the progress of textile fibres, collagen fibres, paper and jute fibres, emulsions, dough, yeasts, metals and minerals through their traditional processes of manufacture. For some of the new products, such as antibiotics, control by microscopical examination is essential. The isolation by micromanipulation of single spores of approved character for the breeding of new lines of yeast and antibiotic-producing fungi (a technique strongly reminiscent of "Brave New World") was well demon-" strated by photomicrograph and working apparatus. The micromanipulators responded to controlling movements with remarkable freedom from backlash.

In analysis, microscopy takes its place with $\mathrm{X}$-ray analysis and the other non-destructive techniques, and it is particularly in this field that the electron microscope finds many applications. Diamond polishing powders, photosensitive grains, pigments, carbon black in rubber, and clay particles in minerals for the ceramic industry are near or beyond the limit of resolution of the light microscope, and examination of raw materials or products containing these particles is now a routine procedure with the electron microscope. As many of the electron micrographs showed, the image is enhanced by shadow-casting. The electron microscope seems to have made a present of 
this technique to the light microscope, perhaps to counter any mistaken impression that there is rivalry between the two instruments. Some fine optical micrographs of metal-shadowed replicas of paint surfaces were displayed.

Analysis by microscopical examination is rarely a straightforward matter of immediate recognition of structure or crystal form but requires the building up of an index by correlation with the results of other methods of examination. This is true not only of the identification and estimation of the constituents of a product (the subject of several exhibits from the metallurgical, ceramic, textile, paper, biological and pharmaceutical industries), but also of the investigation of the causes of defects. This latter duty of microscopy was well demonstrated by an exhibit showing the methods used in examining the crystalline inclusions in glass. This exhibit, by the Glass Technology Department of the University of Sheffield, was supported by many photcmicrographs and sections of identified crystal forms, which are often quite different in shape from the erystal growths in their free state. Such a bold and extensive display of the range of defects possible in a single product could perhaps only have been staged by an impartial body; so, to gratitude for the instruction received is added the prayer that the wrath of the glass industry may not have descended upon the University of Sheffield.

From accidental defect we may descend to adulteration and downright swindle. A most interesting exhibit by the Pharmaceutical Society of Great Britain showed how fraudulent substitutes for the basic crude drugs may be detected.

Metallurgy owes much to the microscope, and as new methods - phase-contrast, interference and electror, microscopy-have been perfected they have naturally been applied to metallography, though perhaps 'naturally' is not quite appropriate for the last of these, since the electron microscope requires a transparent object; for examination at the highest magnifications the metallurgist must therefore rely on transparent replicas of the surface conformation. Among the several examples of replica technique was a photographic demonstration of the remarkable fidelity of reproduction by the replica; optical and electron micrographs of the same area of a metal specimen showed identical features, though the resolution of fine detail was clearer in the electron micrograph since at the magnification used $(\times 4,000)$ some empty magnification was being obtained with the light microscope.

Many special devices were on show, headed by the historic microscope specially ordered by the firm of Whitbread and Co. for Pasteur's use in his investigation of the brewing process. Three reflecting microscopes were shown, one with a long working-distance for use with a furnace ; the other two were for infrared spectrometry, which has become a valuable method of micro-analysis. Several other exhibits of apparatus for special purposes and techniques for measuring physical quantities must, for lack of space, be passed over, but a final word must be spared to note the concentration of microscopical technique being brought to bear by the National Coal Board on the problem of disease due to airborme dust.

The exhibition was well attended, and it is to be hoped that further opportunities will be given to microscopists to display the versatility of their noble instrument.

K. M. GREENLAND

\section{PROBLEMS OF THE LEFT-HANDED}

CTUDIES have been made of the probable 'hand. $S$ edness' of prehistoric man by investigating the various relics of his tools and weapons. It appears from the way they are carved that prehistoric man was preponderantly right-handed. The choice of one hand, usually the right but occasionally the left, and not either hand indiscriminately, is characteristic of man. It would seem that ambidexterity is an animal rather than a human characteristic. These and related problems have recently been discussed by M. M. Clark (Health Education, 9, No. 3; July 1951).

Clark suggests there is no adequate explanation why man should choose one hand and become proficient with it, while his animal ancestors usually used both. Nor can any adequate reason be put forward to explain men's preference for the right hand; and although to be left-handed in a right-handed society has numerous disadvantages, in spite of attempts to stamp it out in Britain, Greece, the United States and France, approximately 4-6 per cent of the population are still left-handed. Why should this be ?

Left-handedness appears to be inherited; how is not known. In certain families there seems to be a high incidence of left-handedness. Some investigators have found that such families also have more than the usual number of twins, so that there might be some connexion between twinning and left-handedness.

That more males than females are left-handed seems to be agreed by investigators and raises the interesting question of whether this is the original distribution, or whether it is a result of the pressure of society. Are more boys than girls born with a tendency to left-handedness, or is it that, while girls are more willing to bow to convention, boys are more inclined to be independent, or stubborn? It would be revealing to carry out a detailed study of the personality traits of left-handed writers, and compare the results with the personality traits of those who were naturally left-handed, or had a tendency to lefthandedness, but did not hold out against the pressure of society. Many difficulties lie in the path of such an investigation, most important of all being the difficulty of finding a reliable test which will measure native handedness. Existing tests do not enable us to distinguish truly right-handed people from those who are naturally left but for some reason use their right. There must be a considerable number of such cases.

The majority of infants prefer one hand to the other, if not at once, then within a few months after birth. It is clear that in a right-handed society the right will be preferred rather than the left. Thus, if a child is born slightly left-handed, the chances are that he will become right-handed. Imitation, training and the right-handed nature of everyday objects are all inducements to his adoption of the right hand.

An ambidextrous child, or rather one who has no preference for either hand, will quickly appear to be right-handed for similar reasons. These are children who could have been good with either hand. If every. one else had used the left, they, too, would probably have done so, and been equally successful.

There is another group which has been given little consideration until recently. Rather than ambidextrous, they might be described as 'ambisinistrous' or poor with either hand. They, too, will veer to right-handedness.

Thus, the left-handed writer will be only the extreme case of left-handedness. 